\title{
Etiologia e evolução das meningites bacterianas em centro de pediatria
}

\author{
Etiology and evolution of bacterial meningitis in a pediatric center
}

\author{
Roberta M.C. Romanelli ${ }^{1}$, Claudete A. Araújo ${ }^{1}$, Miriam W. Dias ${ }^{2}$, \\ Fernando Boucinhas ${ }^{3}$, Inácio R. Carvalho ${ }^{3}$, Nelson R.L. Martins ${ }^{3}$, Heliane B.M. Freire ${ }^{4}$
}

\section{Resumo}

Objetivo: determinar a prevalência dos agentes etiológicos das meningites bacterianas em serviço de referência, no atendimento de doenças infecciosas para o estado de Minas Gerais, e verificar a resposta ao tratamento utilizado.

Métodos: estudo descritivo em que foram incluídas todas as crianças com diagnóstico provável de meningite, admitidas na instituição no período de junho a novembro/99.

Resultados: obteve-se 210 casos de meningite, sendo 111 casos de etiologia bacteriana (52,9\%). Destes, 52 casos foram diagnósticos prováveis (por alteração do liquor rotina) e 59 com diagnósticos de certeza (por cultura e/ou isolamento de antígeno). Os principais agentes isolados foram, em ordem decrescente, $H$. influenzae, $N$. meningitidis e S.pneumoniae. O tratamento inicial para a faixa etária de três meses a cinco anos foi ampicilina e cloranfenicol, sendo posteriormente restrito para penicilina em casos de meningococo e pneumococo, e para cloranfenicol nos casos de H.influenzae. A mudança para antimicrobiano de maior espectro foi realizada com base em dados clínicos ou laboratoriais, não havendo isolamento de microorganismo resistente.

Conclusões: o acompanhamento do perfil epidemiológico das meningites deve ser contínuo, e cada serviço deve se basear em dados locais para direcionar a terapia antimicrobiana. A monitorização contínua dos agentes prevalentes em cada instituição e de sua resistência é fundamental para a escolha antimicrobiana, atuando com menor interferência na colonização individual, sem contribuir para a crescente resistência dos agentes responsáveis pelas infecções meníngeas.

J Pediatr (Rio J) 2002; 78(1):24-30: meningite, líquido cefalorraquidiano, antimicrobiano.

\begin{abstract}
Objective: to establish the prevalence of the etiological agents of bacterial meningitis in a reference center for the treatment of infectious diseases in the state of Minas Gerais.

Methods: descriptive study including all children with probable diagnosis of meningitis between June/1999 and November/1999.

Results: there were 210 cases of meningitis, and 111 (52.9\%) were caused by bacteria. Actually, 52 were probable bacterial meningitis (with liquor alterations) and 59 were confirmed (with culture and/or antigen tests). The main agents were: Haemophilus influenzae, Neisseria meningitidis and Streptococcus pneumoniae. The initial treatment for children aged between three months and five years consisted of ampicillin and chloramphenicol. Later, the antibiotic was changed to penicillin in cases of Neisseria meningitidis and Streptococcus pneumoniae. and to chloramphenicol in cases of Haemophilus influenzae. Extended spectrum antimicrobial agents were used on clinical or laboratory basis, but resistant microorganisms were not found in cultures.

Conclusions: the epidemiology of meningitis should be continuous and should consider local data in order to guide antimicrobial therapy. The continuous monitoring of the prevalent agents in each institution and their resistance is fundamental to the selection of antimicrobial drugs, preserving the antimicrobial agents, and causing less interference with individual colonization, without contributing to the increasing resistance of the agents responsible for meningeal infections.
\end{abstract}

J Pediatr (Rio J) 2002; 78 (1):24-30: meningitis, cerebrospinal fluid, antimicrobial agents.

1. Especialista em pediatria, mestranda pelo Departamento de Pediatria, UFMG

2. Especialista em Pediatria.

3. Preceptor da Residência em Pediatria, CGP-FHEMIG.

4. Professora Adjunta-Doutora - Departamento de Pediatria da Faculdade de Medicina-UFMG, Coordenadora da Residência em Pediatria-FHEMIG.

Artigo submetido em 30.10 .00 , aceito em 08.08.01. 


\section{Introdução}

As meningites bacterianas constituem importante causa de morbimortalidade na infância. Os principais agentes etiológicos são: $H$. influenzae $b$ (Hib), $N$. meningitidis (meningococo) e $S$. pneumoniae (pneumococo) ${ }^{1,2}$. Nos países desenvolvidos, a infecção pelo Hib apresentou mais de $90 \%$ de redução em sua incidência após introdução da vacinação conjugada, que produz imunidade duradoura e interfere no estado de portador ${ }^{3-5}$. Em nosso país, a vacinação iniciada na rede pública em julho de 1999 já demonstra resultados, pois dados do Ministério da Saúde indicam diminuição dos casos notificados de meningite por Hib. Na década de 90 , a média anual de 1.548 casos foi substituída por apenas 106 casos notificados em todo o Brasil, no ano de $2000^{6}$.

Como o pneumococo passou a ser a principal causa de meningite bacteriana em países desenvolvidos, os esforços se concentraram para o desenvolvimento de uma vacina conjugada frente a este agente ${ }^{3,4,7,8}$. No calendário vacinal de 2001 dos Estados Unidos, foi incluída a vacina conjugada heptavalente para pneumococo ${ }^{9}$, devendo ser considerada para proteção dos sorotipos incluídos em sua composição.

A literatura registra, em diversos países, o surgimento de cepas de pneumococo resistentes, com prevalência crescente em alguns locais, embora as diferenças regionais em sua incidência determinem a necessidade de se obter o perfil de sensibilidade desse agente em cada instituição. Essa é a justificativa para enfatizar a importância do isolamento do pneumococo como causa de infecção meníngea bacteriana $^{3,4,7,9,10}$.

As discussões sobre o antimicrobiano de primeira escolha são amplas, variando com a epidemiologia local, custo e evolução clínica ${ }^{2-4,12-14}$. O isolamento dos agentes etiológicos das infecções meníngeas bacterinas é fundamental para terapêutica específica, adequada aos padrões de sensibilidade obtidos nos diversos centros.

O objetivo do presente estudo é a análise da prevalência por agentes e do tratamento empregado nos pacientes com meningite bacteriana, em serviço de referência para doenças infecciosas, no estado de Minas Gerais.

\section{Métodos}

Estudo descritivo, prospectivo, incluindo todos os pacientes atendidos no Centro Geral de Pediatria - Fundação Hospitalar do Estado de Minas Gerais, no período de junho a novembro de 1999, com o diagnóstico provável de meningite bacteriana, estabelecido com base nas manifestações clínicas e nas alterações citobioquímicas no exame do liquor rotina. O serviço é considerado o centro de referência para doenças infecto-contagiosas em todo o estado de Minas Gerais. O protocolo foi submetido ao Comitê de Ética do hospital e, por não haver interferência dos pesquisadores na condução dos casos atendidos conforme a rotina do serviço, não foi necessária a obtenção do consentimento por escrito.

Os critérios seguidos para definição de liquor alterado foram $^{1,15,16 \text { : }}$

- celularidade: normal se $\leq 10 \mathrm{cels} / \mathrm{mm}^{3}$; aumento discreto de 11 a 50 cels $/ \mathrm{mm}^{3}$; aumento moderado de 51 a 200 cels $/ \mathrm{mm}^{3}$; aumento significativo se $>200$ cels $/ \mathrm{mm}^{3}$;

- glicose: normal se $>45 \mathrm{mg} / \mathrm{dl}$ (ou $>2 / 3$ da glicemia); diminuída se $\leq 45 \mathrm{mg} / \mathrm{dl}$;

- proteínas: normal se $\leq 40 \mathrm{~g} / \mathrm{l}$; aumento discreto de 41 a $100 \mathrm{~g} / \mathrm{l}$; aumento significativo se $>100 \mathrm{~g} / \mathrm{l}$.

Para o diagnóstico de meningite bacteriana foram considerados os seguintes critérios:

- diagnóstico de certeza: isolamento no liquor do agente em cultura e/ou pesquisa de antígeno positivo e/ou hemocultura positiva associada às alterações do liquor rotina $^{17}$;

- diagnóstico provável: celularidade liquórica com aumento moderado ou significativo; glicorraquia diminuída; proteinorraquia com aumento significativo.

O diagnóstico de provável meningite viral foi estabelecido através das alterações da citobioquímica liquórica de rotina: celularidade com aumento discreto ou moderado, glicose normal, proteína com aumento discreto.

O antibiótico de escolha para a abordagem inicial do tratamento foi realizado conforme a idade do paciente $^{3,4,7,11,14}$, e a posterior restrição do espectro de antibiótico feita de acordo com o agente isolado, seguindo o protocolo local baseado na literatura mundial $3,4,7,11,14$.

Esse protocolo (Figura 1) define como antibioticoterapia inicial:

- ampicilina e cefalosporina de $3^{\mathrm{a}}$ geração para recémnascido;

- cefalosporina de $3^{\mathrm{a}}$ geração para os pacientes de um mês a três meses;

- ampicilina e cloranfenicol para aqueles de três meses a cinco anos;

- ampicilina para maiores de cinco anos.

A restrição do espectro de antibiótico é definida com o agente isolado:

- H. influenzae: mantido apenas o cloranfenicol (se utilizada a associação ampicilina + cloranfenicol) ou cefalosporina (se iniciada previamente);

- N. meningitidis: modificada para penicilina cristalina;

- S. pneumoniae: modificada para penicilina cristalina.

A utilização ou troca de antimicrobianos para aqueles de maior espectro foram definidas pela evolução clínica, por piora laboratorial, por complicações e/ou resistência ao antibiograma (método Kirby-Bauer) ${ }^{18}$. 


\section{GRUPO DE INFECTOLOGIA PEDIÁTRICA DO CENTRO GERAL DE PEDIATRIA}

\section{Abordagem da Meningite Bacteriana}

1. ABORDAGEM GERAL

A. Suporte do padrão hemodinâmico

B. Não deverá ser feita restrição hídrica

C. Uso de corticóide:

- usa-se dexametasona $0,15 \mathrm{mg} / \mathrm{kg} / \mathrm{dose}$ EV de $6 / 6$ horas, 30 minutos antes de primeira dose de ATB. Prescrever por quatro dias, no total de 16 doses.

- se recebeu ATB venoso previamente, não fazer o corticóide.

D. Abordagem da crise convulsiva na meningite (protocolo específico)

\section{ABORDAGEM ESPECÍFICA}

A. Meningite neonatal (até 1 mês de vida):

- Primeiros sete dias de vida: cefotaxima e ampicilina.

- Indicar cefotaxima após sétimo dia de vida se existir fator de risco para hiperbilirrubinemia.

- Após o sétimo dia de vida: ceftriaxona e ampicilina.

- Se suspeita ou confirmação de sepse tardia por S. aureus, associar oxacilina ou vancomicina ao esquema.

- Se RN com sepse, repetir punção lombar com 24-36h de tratamento se a primeira punção foi normal e existe BGN na hemocultura.

B. Lactente de um a três meses:

- Usar ceftriaxona como monoterapia (intervalo de 24/24h; usar de 12/12h se pneumococo resistente).

- O tempo de tratamento dependerá do agente etiológico.

- Etiologia indeterminada: 7 a 14 dias, dependendo da evolução clínica do paciente.

\section{Meningite meningocócica:}

- Se for isolado meningococo na cultura e/ou pesquisa de antígeno no LCR, prescrever penicilina G cristalina até completar cinco dias de tratamento. Punção de controle deve ser feita com cinco dias completos de ATB (se evolução sem intercorrências).

\section{Meningite por H. influenzae:}

- Se for identificado o $H$. influenzae no LCR, suspender a ampicilina e manter o cloranfenicol no total de sete a dez dias. Punção de controle deve ser realizada com sete dias completos de ATB (se evolução sem intercorrências).

E. Meningite por pneumococo:

- O antibiótico de primeira escolha é a penicilina $\mathrm{G}$ cristalina.

- Se pneumococo penicilino-resistente, prescrever ceftriaxona (ou cefotaxima se existe complicação supurativa do parênquima cerebral).

- Se pneumococo resistente à ceftriaxona ou cefotaxima, associar vancomicina.

- Punção de com dez dias completos de ATB (se evolução sem intercorrências).

F. Meningite bacteriana com etiologia indeterminada:

- RN: até o sétimo dia de vida - cefotaxima e ampicilina após o sétimo dia de vida - ceftriaxona.

- Lactente de um a três meses: ceftriaxona.

- De três meses a cinco anos completos: ampicilina e cloranfenicol.

- Acima de cinco anos: ampicilina.

G. Tempo de tratamento conforme a etiologia da meningite (se evolução sem intercorrências)

- RN: Streptococcus e Listeria - 14 dias; S. aureus e BGN - 21 dias.

- Meningococo: cinco dias de ATB.

- H. influenzae: sete a dez dias de ATB.

- Pneumococo: dez a 14 dias de ATB.

- Etiologia indeterminada: sete a 14 dias, dependendo da evolução clínica.

H. Recomendações para repetir punção lombar em 24-36 horas de ATB:

- Todos RN com sepse por BGN e punção inicial normal.

- Meningite por pneumococo resistente.

- Pacientes com evolução clínica não satisfatória: puncionar quando necessário, de acordo com a avaliação clínica.

I. Pleocitose persistente:

- Presença no LCR de células acima de $60 \mathrm{~mm}^{3}$ em crianças adequadamente tratadas para meningite bacteriana.

- Não é critério de manutenção de ATB, desde que não acompanhada de outras alterações no LCR e na clínica da criança.

- Se suspeita de pleocitose persistente, manter ATB em uso e repuncionar em 72h.

Figura 1- Protocolo 
Nas infecções meningocócicas também foram avaliados os fatores prognósticos, definidos como aparecimento de petéquias nas primeiras 12 horas, sinais de choque, contagem global de leucócitos normal ou diminuída $(<5000$ leucócitos $/ \mathrm{mm}^{3}$ ), velocidade de hemossedimentação(VHS) normal ou diminuída e isolamento do agente em cultura de liquor, mas sem pleocitose ${ }^{19,20}$.

\section{Resultados}

Foram analisadas 210 crianças internadas com o diagnóstico de meningite estabelecido através das alterações clássicas do liquor rotina, no período de junho a novembro/99. Foram $131(62,4 \%)$ pacientes do sexo masculino e $70(37,6 \%)$ do feminino. A mediana da idade foi de 25 meses, e o tempo médio de internação de 12,2 dias. Dos 210 casos, 99 foram considerados de etiologia presumivelmente viral $(47,1 \%)$, e 111 de etiologia presumivelmente bacteriana $(52,9 \%)$. Das meningites bacterianas, 52 tinham diagnóstico provável $(46,8 \%)$, e 59 de certeza $(53,2 \%)$. Destes 59 casos, identificou-se o $H$. influenzae b em 25, N.meningitidis em 17, S. pneumoniae em 15, um caso de $E$. coli em recém-nascido de 12 dias de vida, e um caso de Salmonella em lactente de quatro meses com quadro intestinal associado. A letalidade da amostra foi de nove casos $(4,2 \%)$, sendo três óbitos em pacientes com infecção meníngea provavelmente bacteriana, dois por $H$. influenzae b, dois por S. pneumoniae; um por $N$. meningitidis e um de provável etiologia virótica. Dezessete pacientes com meningite necessitaram de atendimento em Centro de Tratamento Intensivo (CTI), sendo sete com $N$. meningitidis, seis com $H$. influenzae $b$ e quatro com $S$. pneumoniae.

As meningites bacterianas comprovadas tiveram características clínicas, diagnóstico, tratamento e evolução analisados separadamente.
Os pacientes com $H$. influenzae $b$ tiveram seu diagnóstico estabelecido conforme os critérios listados na Tabela 1. À admissão, dos 25 pacientes, 24 apresentaram febre e 19 tinham sinais meníngeos. Destes, a maioria (13 casos- $52 \%$ ) apresentava-se sem alterações do estado de consciência (Tabela 2). O tratamento foi completado, na maioria dos casos, com cloranfenicol (11 casos - 44\%) (Tabela 3). Em relação à evolução clínica, 18 dos pacientes tiveram alta como curados, cinco com alterações neurológicas e dois faleceram.

Houve 17 pacientes com meningite por $N$. meningitidis (Tabela 1). Como manifestações clínicas, observou-se febre, presente em todos os casos, petéquias ou sufusões hemorrágicas em 13 casos e sinais meníngeos em 10 casos. O estado de consciência no momento da hospitalização está relatado na Tabela 2. O tratamento empregado consistiu em penicilina cristalina, quando obtido o diagnóstico de certeza (Tabela 3). Em relação à evolução clínica deste grupo, ocorreu apenas um óbito, duas crianças apresentavam alterações neurológica à alta, e 14 receberam alta como curadas. Dos fatores prognósticos de gravidade da doença meningocócica ${ }^{19,20}, 13$ pacientes apresentavam petéquias nas primeiras 12 horas e/ou choque e um deles com global de leucócitos diminuída.

A meningite por S. pneumoniae foi encontrada em 15 casos (Tabela 1). Como sinais e sintomas, a febre foi relatada em todos os casos e os sinais meníngeos em 12 casos. O estado de consciência variou de normal a torporoso (Tabela 2). O tratamento foi restrito para a penicilina em oito casos (Tabela 3). Doze dos 15 casos evoluíram para cura (incluindo os oito tratados com penicilina) e apenas um caso apresentou déficit neurológico à alta hospitalar. Dois evoluíram para óbito na primeira semana de tratamento no CTI.

Tabela 1 - Diagnóstico laboratorial da etiologia das meningites bacterianas no Centro Geral de PediatriaFHEMIG

\begin{tabular}{lcccccc}
\hline Material & H. influenzae & $\%$ & N.meningitidis & $\%$ & S.pneumoniae & $\%$ \\
\hline Cultura liquor & 6 & 24 & 4 & 23,5 & 5 & 33,3 \\
Pesquisa de antígenos & 2 & 8 & 0 & 0 & 5 & 33,3 \\
Cultura + Pesquisa & 17 & 68 & 11 & 64,7 & 5 & 33,3 \\
Hemocultura & 0 & 0 & $2 *$ & 11,8 & 0 & 0 \\
\hline Total & 25 & 100 & 17 & 100 & 15 & 100 \\
\hline
\end{tabular}

*Associada a diagnóstico de púrpura febril e rotina de liquor alterada 
Tabela 2 - Sinais e sintomas à internação dos pacientes com meningites bacterianas no Centro Geral de Pediatria- FHEMIG

\begin{tabular}{lcccccc}
\hline Material & H. influenzae & $\%$ & N.meningitidis & $\%$ & S.pneumoniae & $\%$ \\
\hline Consciência & & & & & & \\
$\quad$ Normal & 13 & 52 & 7 & 41,2 & 5 & 33,3 \\
$\quad$ Sonolência & 4 & 16 & 3 & 17,6 & 5 & 33,3 \\
$\quad$ Torpor & 3 & 12 & 5 & 29,4 & 3 & 20,0 \\
$\quad$ Coma & 4 & 16 & 0 & 0 & 0 & 0 \\
$\quad$ Ignorado & 1 & 4 & 2 & 11,8 & 2 & 13,3 \\
Febre & 24 & 96 & 17 & 100 & 15 & 100 \\
Sinais meníngeos & 19 & 76 & 10 & 58,8 & 12 & 80 \\
\hline
\end{tabular}

O tempo médio de tratamento do H.influenzae, $N$. meningitidis e $S$. pneumoniae de evolução sem intercorrências foi, respectivamente, 13,2 dias, 8,4 dias e 10,6 dias, excluindo-se os pacientes com complicações e que evoluíram para óbito.

É importante citar que durante o período da coleta de dados foram puncionadas 83 crianças de zero a três meses e todas as amostras de liquor tiveram realizada cultura para Listeria monocytogenes, sendo todas negativas. Foram obtidos apenas 15 de provável meningite bacteriana, três presumivelmente viróticas e um de provável meningite tuberculosa.

\section{Discussão}

O diagnóstico das meningites bacterianas com a identificação do agente causal possibilitando a redução do espectro do antibiótico empregado é fundamental para se evitar associações desnecessárias ou o uso indiscriminado de antimicrobianos de largo espectro.

A identificação de 46, 8\% de indeterminação etiológica observada na presente investigação é considerada extremamente elevada, refletindo a realidade com a qual os hospitais públicos de referência têm-se deparado. Este estudo alerta para a urgência de melhoria laboratorial, das condições de estocagem e de transporte das amostra liquóricas. A letalidade de 4,2\% encontra-se dentro de faixas relatadas na literatura $1,13,21$.

Entre os sinais e sintomas, a febre foi o achado predominante, estando os sinais meníngeos presentes em 41 casos. Ressalta-se que, em 25 pacientes, o estado de consciência foi considerado normal à admissão. Esses dados confirmam a possibilidade de ausência de sinais e sintomas específicos, dificultando a suspeita diagnóstica de meningite, que deve ser sempre lembrada, principalmente em crianças de baixa idade que podem não localizar o acometimento meníngeo.

Tabela 3 - Tratamento inicial dos pacientes com meningite bacteriana no Centro Geral de Pediatria- FHEMIG

\begin{tabular}{lcccccc}
\hline Material & H. influenzae & $\%$ & N.meningitidis & $\%$ & S.pneumoniae & $\%$ \\
\hline Penicilina & 0 & 0 & 8 & 47,0 & 8 & 53,3 \\
Ampicilina & 0 & 0 & 4 & 23,5 & 2 & 13,3 \\
Cloranfenicol & 11 & 44 & 0 & 0 & 0 & 0 \\
Cefalosporina 3 & 8 & 32 & 2 & 11,8 & 4 & 26,7 \\
Ampicilina + Cloranfenicol & 5 & 20 & 2 & 11,8 & 0 & 0 \\
Cefalosporina 3a + Vancomicina & 0 & 0 & 1 & 5,9 & 1 & 6,7 \\
Cefepima + Gentamicina & $1 *$ & 4 & 0 & 0 & 0 & 0 \\
\hline Total & 25 & 100 & 17 & 100 & 15 & 100 \\
\hline
\end{tabular}

* Imunossuprimido 
Dos 15 pacientes de zero a três meses com provável meningite bacteriana, apenas três apresentaram cultura de liquor positiva. Esses achados indicam a necessidade de se trabalhar com grande amostra para se definir a importância de Listeria como agente causal de meningite em nosso meio e a real necessidade da associação de ampicilina e cefalosporina para a abordagem empírica inicial das infecções meníngeas em crianças dessa faixa etária.

Em relação ao tratamento para o H.influenzae, a redução de espectro antimicrobiano, com o emprego isolado de cloranfenicol em $44 \%$ da amostra, possibilitou comprovar a efetividade desse antimicrobiano. Devido à crescente resistência deste agente à ampicilina, também com variações locais, e na ausência de antibiograma rotineiro, constitui abordagem segura e de baixo custo. A instituição onde esta investigação ocorreu implantou, no ano de 2000, o antibiograma através do E-teste ${ }^{18}$, com o objetivo de se atuar de maneira mais rápida e eficaz na orientação à terapêutica com antimicrobianos.

Em cinco casos (20\%) de meningite por H.influenzae, manteve-se o esquema antibiótico inicial devido à chegada tardia dos resultados. Este é mais um fator determinante da manutenção de associações antibióticas que deve ser melhorado. Dos oito pacientes com infecção peloH.influenzae que usaram cefalosporina, não houve isolamento de microorganismo resistente ao esquema inicial, e em quatro (50\%), justificou-se alteração pela piora clínica dos pacientes; sendo três devido a complicações (empiema ou cerebrite). Em um neutropênico febril, optou-se por esquema com cefepima e gentamicina. Dos cinco pacientes com alterações neurológicas à alta, quatro haviam terminado tratamento com cefalosporina e apenas um apresentava complicação.

Dos pacientes com $N$. meningitidis, o tratamento foi posteriormente restrito para penicilina ou ampicilina em 12 casos $(70 \%)$. O esquema inicial foi mantido em dois casos devido à demora na obtenção da identificação do agente envolvido. A ceftriaxona foi empregada em um caso devido à piora clínica e laboratorial, e em um devido à complicação. A associação vancomicina e ceftriaxona foi empregada devido à piora clínica do paciente, não tendo se baseado no isolamento de microorganismos resistentes. Novamente, deve-se enfatizar a necessidade de se agilizar o auxílio fornecido pelos achados laboratoriais pela freqüência de se alterar conduta baseando-se apenas em critérios clínicos.

Um dos assuntos mais discutidos na literatura, atualmente, é a resistência do pneumococo. Embora a amostra estudada seja reduzida ( 15 casos), em nenhuma das culturas (método Kirby-Bauer) houve identificação de resistência. Foi utilizada penicilina em oito casos, após identificação do agente responsável pela infecção meníngea, e em nenhum destes observou-se evolução para o óbito ou complicação neurológica. A cefalosporina foi empregada em dois casos admitidos inicialmente no CTI, em um caso devido à complicação e em outro devido às alterações laboratoriais (liquor rotina). O paciente em quem se substituiu o esquema para cefalosporina e vancomicina apresentou piora clínica e empiema.

Estas observações são importantes, pois a gravidade da doença não está relacionada com o padrão de resistência $^{11,12,17,22}$. A escolha de antimicrobianos deve estar relacionada com a realidade de cada serviço. A literatura mundial registra taxas variáveis de pneumococo resistente. A resistência plena necessita dosagem de concentração inibitória mínima (CIM) acima de $2 \mu \mathrm{g} / \mathrm{ml}$. A sensibilidade moderada é definida por CIM de $0,1 \mathrm{a} 1 \mu \mathrm{g} / \mathrm{ml}$. A avaliação extremamente bem conduzida por Brandileone et al. $(1997)^{23}$ mostrou que o pneumococo resistente existe em taxas variadas, chegando a $25 \%$ em alguns locais, sendo prevalente onde se emprega antibióticos de largo espectro, como a cefalosporina de $3^{\mathrm{a}}$ geração.

Como o presente estudo apresenta pequeno número de casos, não se pode definir associação causal entre a freqüência de alterações neurológicas à alta e o uso de cefalosporina de $3^{\mathrm{a}}$ geração. É interessante ressaltar que esses antibióticos, com excelente penetração na barreira hematoliquórica, têm dados comparáveis de morbidade e letalidade em relação aos esquemas clássicos nas diversas idades. Esse foi o fator que estimulou pesquisa da regulação do processo inflamatório como alternativa para obtenção de melhor evolução das meningites bacterianas, pois o uso de antibióticos potentes manteve índices de letalidade e morbidade $^{17,22}$.

Em vários países em desenvolvimento, o $H$. influenzae ainda é o agente predominante das meningites. Com a implantação progressiva da vacinação anti-Hib, o pneumococo poderá se constituir maior problema no manejo das meningites, especialmente se comprovar-se que a vacina conjugada frente ao pneumococo atue erradicando, no portador, as cepas sensíveis deste agente, criando possibilidade de colonização por bactérias resistentes.

A monitorização contínua do perfil dos agentes prevalentes em cada instituição e de sua resistência é fundamental para a escolha antimicrobiana no serviço e para que se preservem antimicrobianos, atuando com menos interferência na colonização individual, sem contribuir para a crescente resistência dos agentes responsáveis pelas infecções meníngeas.

\section{Agradecimentos}

Agradecimento especial à equipe de Neurologia do CGP, que muito contribuiu para o trabalho: Dr. Cristóvão de Castro Xavier, Dra. Valéria Loureiro Rocha, Dra. Karina Soares Loufti e Dra. Luciana Dolabella Veloso.

\section{Referências bibliográficas}

1. Feigin RD, Pearmon E. Bacterial Meningitis. In: Feigin RD, Cherry JD. Textbook of Pediatric Infectious Diseases. $4^{\mathrm{a}}$ ed. Philadelphia: WB Saunders; 1998. p.400-29. 
2. Saez-Llorens X, McCracken Jr GH. Antimicrobial and antiinflammatory treatment of bacterial meningitis. Infect Dis Clin North Am 1999; 13: 619-35.

3. Quagliarello VJ, Scheld WM. Treatment of bacterial meningitis. N Engl J Med 1997;336: 708-16.

4. Wubbel L, McCracken GH. Management of Bacterial Meningitis:1998. Pediatrics in Review 1998; 19(3): 78-84.

5. Forleo-Neto E, Oliveira CF, Maluf EMCP, et al. Decrease point prevalence of Haemophilus influenza Type b (Hib) oropharyngeal colonization by mass immunization of Brazilian children less than 5 years old with Hib polyribosylribitol phosphate polysaccharide - tetanus toxoid conjugate vaccine in combination with diphtheria- tetanus toxoids - pertussis vaccine. J Infect Dis 1999; 180 (4): 1153-8.

6. Ministério da Saúde. Fundação Nacional de Saúde. Grupo Técnico em Meningite - 2000.

7. Gold R. Epidemiology of bacterial meningitis. Infect Dis Clin North Am1999; 13: 515-25.

8. Eskola J, Antila M. Pneumococcal conjugate vaccines. Pediatr Infect Dis J 1999; 18(6):543-51.

9. Center of Diseases Control and Prevention. Childhood Immunization Schedule. Morbidity and Mortality Weekly Report 2001; 50(1): 7-10.

10. Dawson KG, Emerson JC, Burns JL. Fifteen years of experience with bacterial meningitis. Pediatr Infect Dis J 1999; 18(9): 816-22.

11. Committee on Infectious Diseases. American Academy of Pediatrics. Therapy for children with invasive pneumococcal infections. Pediatrics 1997; 99(2):289-99.

12. Freire LMS. Tratamento de suporte das meningites bacterianas na infância. Rev Paul Pediatria 1998; 16(2): 104-11.

13. Peltola H. Controversies in the management of childhood meningitis. J Med Microbiol 1997; 46 (11): 901-2.

14. Peltola H, Anttila M, Renkonen OV. Randomised comparison of chloramphenicol, ampicillin, cefotaxime and ceftriaxone for childhood bacterial meningitis. Lancet 1989; I: 1281-87.

15. Campos CEOP, Santos NNQ, Takahashi MN, Kawamura IE, Damião SV, Kushnaroff TM, et al. Aspectos dos líquidos cefalorraquidianos nas meningites bacterianas. Rev Soc Bras Med Trop 1994; 27 (2): 87-91.
16. Saez Llorens X, McCracken GH. In: Katz SL, Gershon AA, Hortez PJ. Krugmans Infectious Diseases of Children. $10^{\mathrm{a}}$ ed. St Louis: Mosby; 1998. p.265-79.

17. Freire HBM, Freire LMS. Meningites bacterianas. In: Tonelli E, Freire LMS. Doenças infecciosas na infância e adolescência. $2^{\mathrm{a}}$ ed. Rio de Janeiro: MEDSI; 2000. p.557-70.

18. Graman PS, Menegus MA. Microbiology laboratory tests. In: Reese RE, Betts RF. Practical approach to infectious diseases. $4^{\mathrm{a}}$ ed. 1996. p.953-59.

19. Tesoro LJ, Selbst SM. Factors affecting outcome in meningococcal infections. AJDC 1991; 145:218-20.

20. Malley R, Inkelis SH, Coelho P, Huskins WC, Kuppermann N. Cerebrospinal fluid pleocytosis and prognosis in invasive meningococcal disease in children. Pediatr Infect Dis J 1998; 17(10): 855-59.

21. Tunkel TB, Greenlee JE. Acute Meningitis. In: Mandell GL, Bennett JE, Dolin R. Principles and practice of infectious diseases. $5^{a}$ ed. Philadelphia: Churchill Livingstone; 2000. p. 959-96.

22. Kaplan SL, Mason EO, Barson WJ, et al. Three-year multicenter surveillance of systemic pneumococcal infections in children. Pediatrics 1998;102(3): 538-45.

23. Brandileone MCC, Di Fabio JL, Vieira VSD, Zanella RC, Casagrande ST, Pignatari AC, et al. Geographic distribution of penicillin resistance of Streptococcus pneumoniae in Brazil: genetic relatedness. Microbial Drug Resistance 1998; 4(3):209-16.

Endereço para correspondência:

Dra. Roberta Maia de Castro Romanelli

Alameda Ezequiel Dias, 345 - $3^{\circ}$ andar - Santa Efigênia CEP 30130-110 - Belo Horizonte, MG

E-mail: romaneli@ rbeep.com.br 